\title{
Morphologies and microstructures of tree-like carbon produced at different reaction conditions in a CVD process
}

\author{
Hai-Long Ma ${ }^{\text {a,c }}$, Dang Sheng Su ${ }^{\text {b }}$, Achim Klein-Hoffmann ${ }^{\text {, }}$, Guo Qiang Jin ${ }^{\text {, }}$ \\ and Xinag-Yin Guo
}

${ }^{\mathrm{a}}$ State Key Laboratory of Coal Conversion, Institute of Coal Chemistry, CAS, Taiyuan 030001, China ${ }^{\mathrm{b}}$ Department of Inorganic Chemistry, Fritz-Haber-Institute of MPG, Berlin 14195, Germany

${ }^{\mathrm{c}}$ Graduate School of the Chinese Academy of Sciences, Beijing 100039, China

\begin{abstract}
Centimeter-size multi-branched tree-like carbon structures have been generated by the catalytic chemical vapor deposition of toluene using ferrocene as the catalyst precursor and investigated by means of SEM, TEM, and EDX. It is found that a temperature of $1000-1200{ }^{\circ} \mathrm{C}$ and a carrier gas flow rate of $1000-2500 \mathrm{ml} / \mathrm{min}$ are necessary for the generation of the carbon trees. Their morphologies and microstructures change greatly with the changing reaction conditions. The fractal dimensions of the trees are calculated to quantitatively investigate the influence of different reaction temperatures on the morphologies.
\end{abstract}

Keywords: Vapor-grown carbon; Chemical vapor deposition; Scanning electron microscopy; Microstructure

\section{Introduction}

Chemical vapor deposition (CVD) is a versatile route suitable for the production of coatings, powders, fibers, and monolithic components [1]. Most metals, many nonmetallic elements such as carbon and silicon as well as a large number of compounds including carbides, nitrides, and oxides can be produced by the CVD process [1]. The CVD of hydrocarbons is a traditional and still powerful method for the preparation of many kinds of carbon materials such as vapor-grown carbon fibers (VGCFs) [2], carbon nanotubes [3], and metal-encapsulated carbon nanoparticles [4].

Recently, different routes including the CVD process have been applied to produce branched and fractal carbon fibers due to their potential applications as reinforcements in composite materials. Zhou et al. developed an approximate theory describing the pull-out of fibers with fractal-tree structure from a matrix to quantify the effects of fractal fibers [5]. Their results showed that composite materials mixed with fractal fibers exhibited much more excellent mechanical properties than those mixed with wire-like fibers. Shi et al. prepared branched carbon nanofibers by an improved CVD method using ferrocene as the catalyst precursor and benzene as the carbon source [6]. Ajayan et al. reported a micrometer-size tree-like carbon structure produced from a flash CVD process of methane [7] and [8]. Shimizu et al. reported the generation of a cedar-tree-forest carbon structure by the DC plasma assisted hot filament CVD [9]. The tree-like structure was formed by the self-assembling of carbon nanotubes, while the nanotubes themselves were not branched. Terranova et al. described the tree-like carbon nanostructures generated by the action of atomic hydrogen on glassy carbon [10]. Murooka et al. found that hot carbon nanoparticles could be assembled into a tree-like structure in the pulse-arcdischarge process [11]. The successful preparation of these branched and tree-like carbon structures suggests that more complex carbon architectures can be obtained through skillful control of the experimental environments.

Recently our research group reported the generation of centimeter-size tree-like carbon structures [12]. These structures were produced from catalytic chemical vapor deposition of toluene. The carbon trees 
have lengths of several centimeters and diameters of $2-10 \mathrm{~mm}$. These trees exhibit dendritic structuresand show fractal characteristics formed by the lateral growth, which is obviously different from the VGCFs grown under similar reaction conditions. From the recent experiments, it has been found that the morphologies and microstructures of the carbon trees can be controlled by the variation of experimental conditions such as the reaction temperature and the carrier gas flow rate. In the present work, we investigate the influence of different reaction conditions on the carbon trees' morphologies and microstructures by means of SEM, TEM, and EDX analysis. The fractal dimensions of the carbon trees are also calculated to quantitatively investigate the influence of different reaction temperatures on the trees' morphologies.

\section{Experimental}

The synthesis of carbon trees is performed as described previously [12]. Briefly, a horizontally placed tubular quartz reactor loaded in a tubular furnace is employed in the experiment. An alumina-coated thermocouple is placed in the tube center. Toluene is used as the carbon source and is introduced into the reactor by argon bubbling at room temperature. The flow rate of argon is controlled at 150-200 $\mathrm{ml} / \mathrm{min}$. Simultaneously, the catalyst precursor (ferrocene) placed at the low temperature part of the furnace is sublimed at about $150{ }^{\circ} \mathrm{C}$ and then is transported by another argon flow with the flow rate of $500-2500 \mathrm{ml} / \mathrm{min}$, which is also used to adjust the total flux passing through the reactor. The reaction temperature is controlled at $1000-1200^{\circ} \mathrm{C}$, and the duration is about $30-90 \mathrm{~min}$. After the reaction the furnace is cooled to room temperature under the protection of argon. The black tree-like product can be collected at the end part of the thermocouple. The temperature dependence of the carbon tree growth is studied by changing the reaction temperature from 1000 to $1200{ }^{\circ} \mathrm{C}$, while the flow rate of the carrier gas (argon) is kept at $1000 \mathrm{ml} / \mathrm{min}$. The influence of the flow rate is obtained by changing the flux from 500 to $2500 \mathrm{ml} / \mathrm{min}$ while keeping the reaction temperature at $1150{ }^{\circ} \mathrm{C}$.

The morphologies and microstructures of the carbon trees are characterized by SEM (S4800 FEG, Hitachi), TEM (CM 200 FEG, Philips), and energy dispersive X-ray (EDX) spectroscopy analysis.

The influence of different reaction temperatures is studied by calculating the fractal dimensions of the trees' SEM images. The calculation is performed with the help of the software named HarFA, which is based on the "box counting method" [13]. In the box counting method, the image of a fractal object is covered with boxes (or squares), and then the number of boxes needed to cover the fractal image completely is evaluated. A logarithmical function of the box size ( $r$, as the $x$-axis) and the number of boxes needed to cover the fractal image ( $N$, as the $y$-axis) will be obtained by repeating this measurement with different sizes of boxes. The slope $D$ of the linear portion of the function $\log N(r)=$ $D(\log (1 / r))+\log k$ is assumed to be the box dimension, which is taken as an appropriate approximation of fractal dimension [13].

\section{Results and discussion}

The SEM images of the carbon trees grown at different temperatures are shown in Fig. 1. It can be seen from the figure that the morphologies of carbon trees are greatly influenced by the reaction temperature. The carbon products obtained at $1000^{\circ} \mathrm{C}$ and $1050{ }^{\circ} \mathrm{C}$ look more like coral (Fig. 1a and b). One cannot find straight and tree-like branches in the carbon structures. On the contrary, the products seem to be formed by the random and simple deposition and aggregation of carbon spheres. These characteristics may further confirm the formation mechanism of the carbon trees [12]. When the reaction temperature is raised to $1100{ }^{\circ} \mathrm{C}$ (Fig. 1c), however, the multi-branched tree-like carbon structures appear. The branches become straighter, smoother, and longer, which demonstrates the great influence of reaction temperatures on the morphologies of the tree branches. The diameter of the tree branches at $1100{ }^{\circ} \mathrm{C}$ is about $8-10 \mu \mathrm{m}$. The tree branches show observably spherulitic nodules because they are formed by the aggregation of the microspheres [12]. With further increase of the reaction temperature, the tree branches continue to become smoother, longer, and thinner (see Fig. 1d and e). The diameter of the tree branches at $1150{ }^{\circ} \mathrm{C}$ and $1200 \mathrm{C}$ is about $5-6 \mu \mathrm{m}$. 

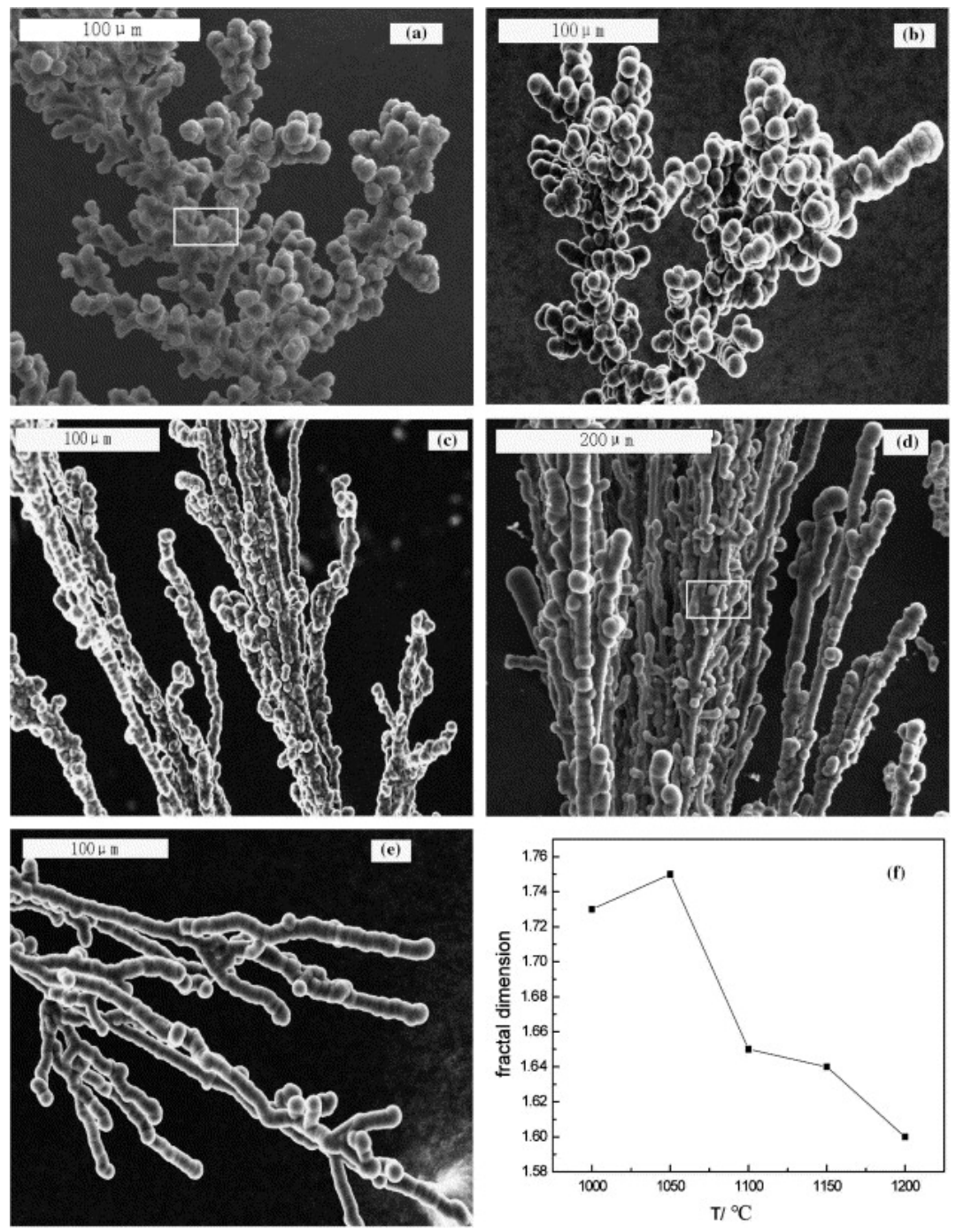

Fig. 1. SEM images showing the temperature dependence of the morphologies of carbon trees while keeping the flow rate of the carrier gas at $1000 \mathrm{ml} / \mathrm{min}$. Temperatures are $1000 \mathrm{C}$ (a), $1050{ }^{\circ} \mathrm{C}$ (b), $1100{ }^{\circ} \mathrm{C}(\mathrm{c}), 1150{ }^{\circ} \mathrm{C}(\mathrm{d})$, and $1200{ }^{\circ} \mathrm{C}(\mathrm{e})$, respectively. And the temperature dependence of the fractal dimensions of the SEM images of the carbon trees (f). The white rectangles in (a) and (d) indicate the area for the EDX analysis shown in Fig. 2.

The influence of reaction temperatures on the trees' morphologies can be explained as follows. As suggested in the previous paper, the carbon trees grow via the aggregation of carbon microspheres and subsequent restructuring processes [12]. At $1000^{\circ} \mathrm{C}$ ( or $1050{ }^{\circ} \mathrm{C}$ ), a great deal of carbon nanoparticles aggregate through collision and then deposit on the thermocouple surface and form the coral-like carbon structures. However, the temperature is still not high enough for the carbon architectures to restructure and form fine morphologies. Therefore, the trees grown at $1000{ }^{\circ} \mathrm{C}$ and $1050{ }^{\circ} \mathrm{C}$ look like rough architectures of carbon spheres. When the reaction temperature is raised to about $1100{ }^{\circ} \mathrm{C}$, the carbon microspheres coalesce with each other more sufficiently. The rough tree branches begin to perform the restructuring process, and then the smooth and fine morphologies are formed. With the further increase of the reaction temperature $\left(1150-1200{ }^{\circ} \mathrm{C}\right)$, the nodular branches become relatively smooth due to the restructuring of tree surfaces.

The temperature dependence of the carbon trees' fractal dimension is shown in Fig. 1f. It can be found from the figure that the fractal dimension decreases with the increase of the reaction temperature. Generally, the fractal dimension can be used to describe the roughness of fractal surfaces [13]. The fractal object usually has a bigger fractal dimension for a rougher surface, and a smaller fractal dimension for a smoother surface. It has been known from the SEM images in Fig. 1 that the carbon trees grown at lower temperatures $\left(1000-1050{ }^{\circ} \mathrm{C}\right)$ have relatively rougher surfaces, therefore, the 
trees have relatively bigger fractal dimensions. Correspondingly, the trees grown at higher temperatures $\left(1100-1200^{\circ} \mathrm{C}\right)$ show smaller fractal dimensions because they have smoother surfaces due to the restructuring of tree surfaces.

The microstructures of the carbon trees at different temperatures have also been studied. The EDX spectra (taken in the area indicated by rectangles in Fig. 1a and d) are shown in Fig. 2. It can be seen that $\mathrm{Fe}$ element is detected from the tree by EDX when the reaction temperature is $1000{ }^{\circ} \mathrm{C}$ (Fig. 2a). However, no $\mathrm{Fe}$ is detected from the trees obtained at $1150{ }^{\circ} \mathrm{C}$ (Fig. 2b). The reason can be found in Fig. 3, which shows the TEM images of cross sections of the trees obtained at different temperatures. At the cross section of the trees obtained at $1000^{\circ} \mathrm{C}$, Fe element can be found widely distributed in the tree branches (Fig. 3a). However, in the tree branches obtained at $1150^{\circ} \mathrm{C}, \mathrm{Fe}$ element can be found only in the central part of the cross sections (see Fig. 3b). In EDX analysis, electron beams can only penetrate through quite finite depth of the sample surface. In the carbon trees obtained at $1000{ }^{\circ} \mathrm{C}, \mathrm{Fe}$ element is distributed in a wide area, also in the part near the surface. However, in the carbon trees obtained at $1150{ }^{\circ} \mathrm{C}, \mathrm{Fe}$ has diffused into the central part of the tree branches and is relatively far from the trees' surface.
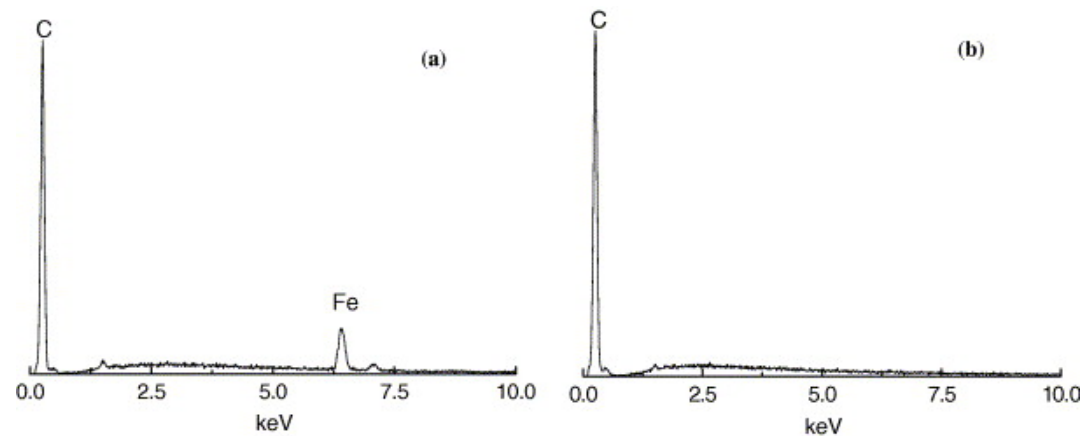

Fig. 2. EDX spectra of the surfaces of carbon trees at different temperatures: (a) $1000 \mathrm{C}$ and (b) $1150{ }^{\circ} \mathrm{C}$.
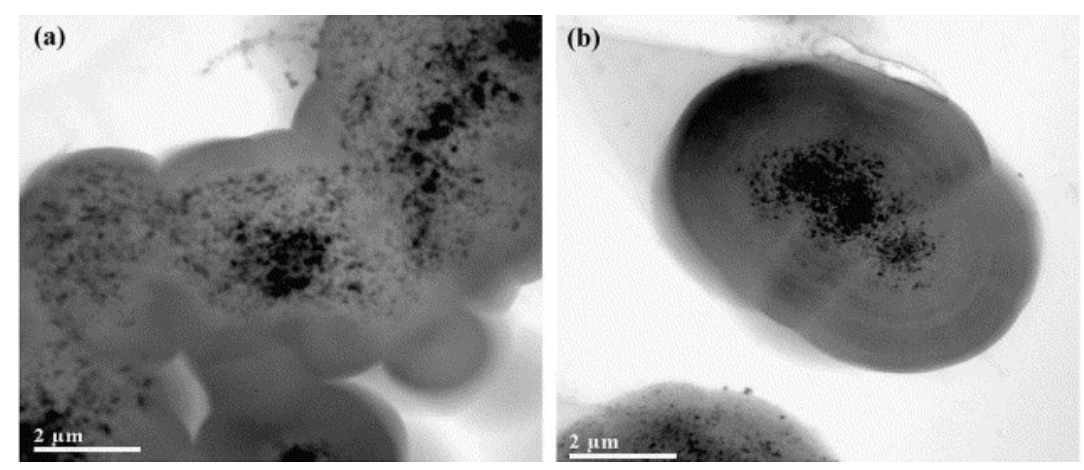

Fig. 3. TEM images of the cross sections of the carbon trees obtained at different temperatures: (a) $1000^{\circ} \mathrm{C}$ and (b) $1150{ }^{\circ} \mathrm{C}$.

The influence of the reaction temperature on Fe distribution in carbon trees is suggested as follows. Under the reaction conditions, Fe nanoparticles formed by ferrocene decomposition are transported to the isothermal zone of the reactor by the carrier gas and are encapsulated by deposited carbon from the pyrolysis of toluene, and the Fe-encapsulated carbon nanoparticles are thus formed. These nanoparticles collide with each other and aggregate into carbon spheres with the size of several microns. The microspheres deposit on the thermocouple end and form the tree-like structures. At reaction temperatures of $1000{ }^{\circ} \mathrm{C}$ and higher, the iron particles encapsulated in the carbon shells are quite active and tend to escape from the carbon shells [14]. These escaped iron particles fuse with each other and perform the enrichment process. Due to the relatively higher density compared to carbon, the 
iron particles concentrate to the central part of the tree branches. Obviously, higher temperatures lead to more complete enrichment, as seen in Fig. 3.

High-resolution TEM images of the carbon trees (Fig. 4) reveal that the graphite lattice fringes at different reaction temperatures $\left(1000{ }^{\circ} \mathrm{C}\right.$ and $\left.1200{ }^{\circ} \mathrm{C}\right)$ almost have a same value of $0.34 \mathrm{~nm}$, which is close to that of the graphite plane (002). This suggests that the difference in the present reaction temperature does not significantly affect the graphitization degree of the carbon trees. From the sample obtained at $1000{ }^{\circ} \mathrm{C}$, a lot of nanoparticles containing iron cores can easily be observed, as shown in Fig. 4a. This result further confirms that the trees are formed by an assembly of iron-encapsulated carbon nanoparticles. For the sample obtained at $1200^{\circ} \mathrm{C}$, however, the TEM observation reveals that most carbon nanoparticles have no iron cores, as shown in Fig. 4b. In addition, there are obvious voids in the nanoparticles' center, and this may indicate that the iron cores have escaped from the nanoparticles. This is also consistent with the above TEM and EDX analysis results, in that the Fe has escaped from the carbon nanoparticles and concentrated to the central part of the tree branches at higher reaction temperatures.
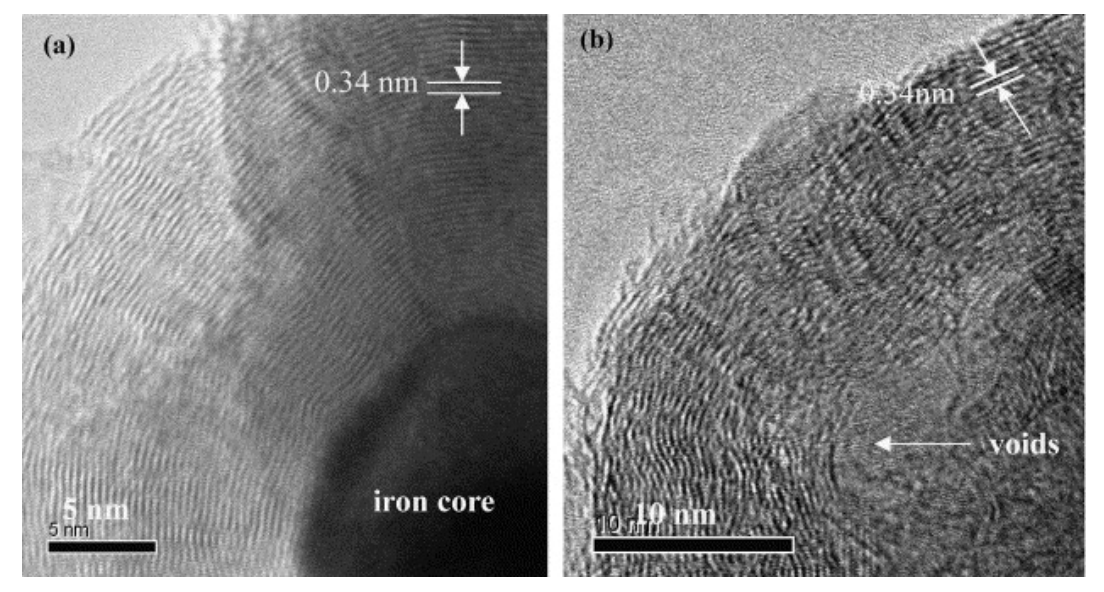

Fig. 4. High-resolution TEM images of the carbon trees obtained at different temperatures: (a) $1000{ }^{\circ} \mathrm{C}$ and (b) $1200^{\circ} \mathrm{C}$.

The SEM images of the carbon trees generated at different flow rates of carrier gas are shown in Fig. 5. It can be seen that no tree-like structures but ordinary vapor-grown carbon fibers are produced when the flow rate is $500 \mathrm{ml} / \mathrm{min}$ (Fig. 5a). However, when the flow rate is raised to $1000 \mathrm{ml} / \mathrm{min}$, the dendritic structures appear (Fig. 5b). The variation of the morphologies of the products at different flow rates suggests that the suitable flow field of carrier gas is quite necessary for the generation of the carbon trees. It also can be seen from Fig. $5 f$ that the diameters of the tree branches are obviously influenced by the flow rate; the diameter increases when the flow rate is raised.

The influence of the flow rate on the growth of the carbon trees is proposed as follows. As suggested in the previous paper, the growth of the carbon trees is related to the special flux field behind the thermocouple end [12]. Many gaseous vortices may appear behind the thermocouple when the flow rate is large enough. The carbon nanoparticles near the thermocouple end are carried into the vortices. These nanoparticles collide with each other and then aggregate into microspheres. The carbon trees are formed when these microspheres are carried to the thermocouple end by the carrier gas flow and perform the deposition and aggregation processes. Therefore, the trees cannot grow when the flow rate is not large enough because not many building blocks (the carbon microspheres) can be generated at low gas flow rates. On the other hand, the collision among the carbon spheres is more frequent and more violent in a flux field with large flow rate. As a result, more carbon spheres and more collision opportunities make it possible to form thicker and stronger tree branches. 

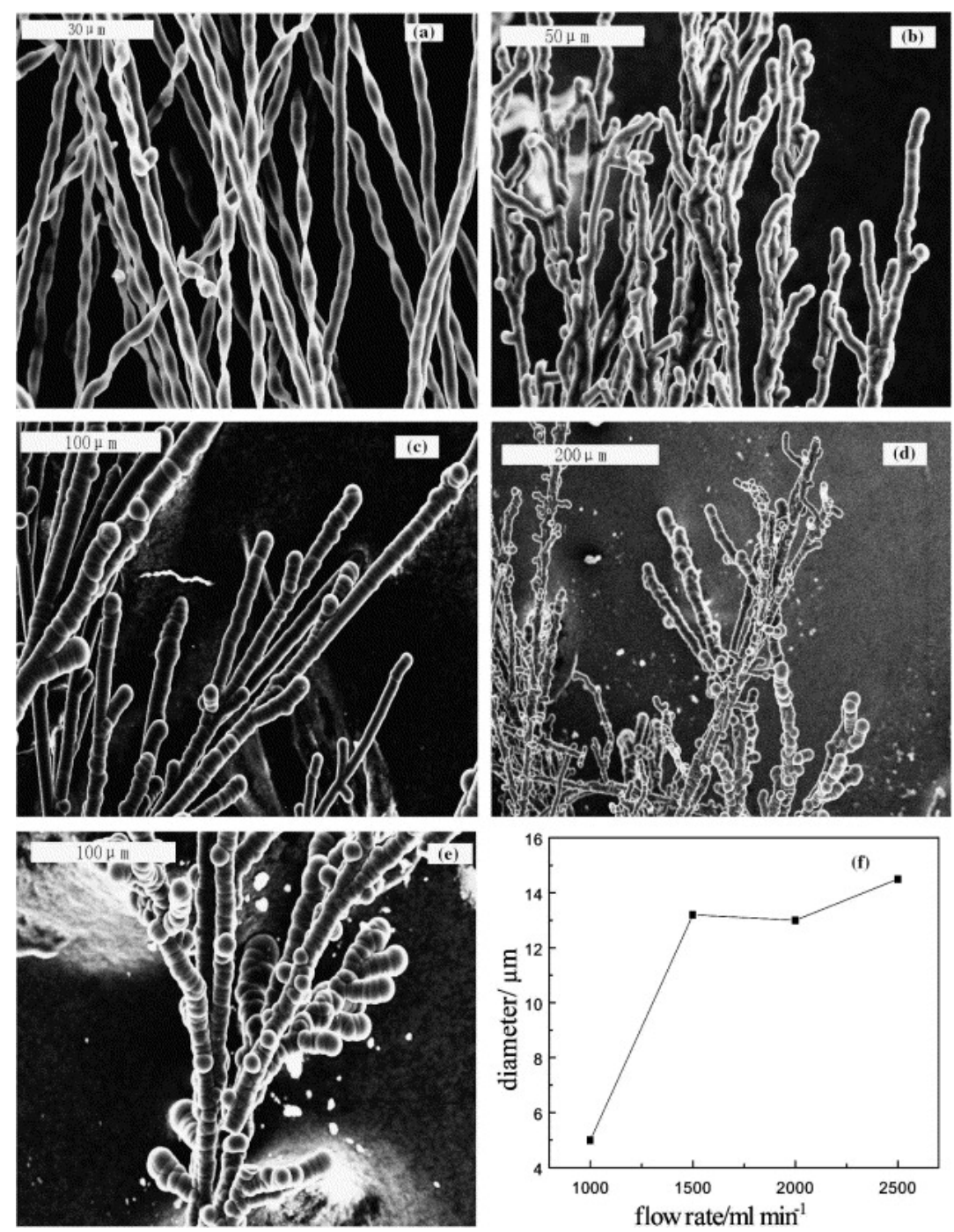

Fig. 5. SEM images showing the flow rate dependence on the morphologies of carbon trees while keeping the reaction temperature at $1150{ }^{\circ} \mathrm{C}$. The flow rates are $500 \mathrm{ml} / \mathrm{min}$ (a), $1000 \mathrm{ml} / \mathrm{min}$ (b), $1500 \mathrm{ml} / \mathrm{min}$ (c), 2000 $\mathrm{ml} / \mathrm{min}$ (d), and $2500 \mathrm{ml} / \mathrm{min}$ (e), respectively. And the diameters of the carbon tree branches at different flow rates of carrier gas (f).

\section{Conclusions}

Centimeter-size multi-branched carbon trees have been prepared from the catalytic chemical vapor deposition of toluene at a reaction temperature of $1000-1200^{\circ} \mathrm{C}$ and a carrier gas flow rate of 1000 $2500 \mathrm{ml} / \mathrm{min}$. The carbon trees grown at lower temperatures $\left(1000-1050{ }^{\circ} \mathrm{C}\right)$ usually show rougher and spherical branches and have larger fractal dimensions; however, the trees obtained at higher temperatures $\left(1100-1200{ }^{\circ} \mathrm{C}\right)$ usually exhibit smoother, longer, and thinner branches and have smaller fractal dimensions. The reaction temperature also affects carbon trees' microstructures and lead to the concentration of iron in the central part of the tree branches. The carrier gas flow rate has an obvious influence on the tree branches. A smaller carrier gas flow rate results in thinner branches and a larger one in thicker branches.

\section{Acknowledgement}

The authors thank Dr. Oldrich Zmeskal for granting permission to use the HarFA software. 


\section{References}

[1] O.P. Hugh, Handbook of chemical vapor deposition (CVD)-principles, technology, and applications (2nd ed.), Noyes, Park Ridge (NJ) (1999) 25-6.

[2] M. Endo, Y.A. Kim, T. Hayashi, K. Nishimura and T. Matusita et al., Vapor-grown carbon fibers (VGCFs): basic properties and their battery applications, Carbon 39 (2001), pp. 1287-1297.

[3] H.W. Zhu, C.L. Xu, D.H. Wu, B.Q. Wei, R. Vajtai and P.M. Ajayan, Direct synthesis of long single-walled carbon nanotubes strands, Science 296 (2002), pp. 884-886.

[4] E. Flahaut, F. Agnoli, J. Sloan, C. O'Connor and M.L.H. Green, CCVD synthesis and characterization of cobalt-encapsulated nanoparticles, Chem Mater 14 (2002), pp. 2553-2558.

[5] S.Y. Fe, B.L. Zhou and C.W. Lung, On the pull-out of fibers with fractal-tree structure and the interference of strength and fracture toughness of composites, Smart Mater Struct 1 (1992), pp. 180185.

[6] Y.F. Shi, H.J. Quan, G.B. Zheng, H. Sano and Y. Uchiyama, Branched carbon nanofibers synthesized by an improved floating catalytic method, J Mater Sci 39 (2004), pp. 1495-1497.

[7] P.M. Ajayan, J.M. Nugent, R.W. Siegel, B. Wei and Ph. Kohler-Redich, Growth of carbon microtrees, Nature 404 (2000), p. 243.

[8] Y.J. Jung, B. Wei, J. Nugent and P.M. Ajayan, Controlling growth of carbon microtrees, Carbon 39 (2001), pp. 2195-2201.

[9] Y. Shimizu, T. Sasaki, T. Kodaira, K. Kawaguchi, K. Terashima and N. Koshizaki, Fabrication of carbon nanotube assemblies on $\mathrm{Ni}-\mathrm{Mo}$ substrates mimics law of natural forest growth, Chem Phys Lett 370 (2003), pp. 774-780.

[10] M.L. Terranova, V. Sessa and M. Rossi, Tree-like carbon nanostructures generated by the action of atomic hydrogen on glassy carbon, Chem Phys Lett 336 (2001), pp. 405-409.

[11] Y. Murooka, Y. Maede, M. Ozaki and M. Hibino, Self-assembling of hot carbon nanoparticles observed by short pulse-arc-discharge, Chem Phys Lett 341 (2001), pp. 455-460.

[12] X.Y. Guo, Macroscopic multi-branched carbon trees generated from chemical vapor deposition of toluene, Carbon 43 (2005), pp. 1098-1100.

[13] Nezadal M, Zmeskal O, Buchnicek M. The box-counting: critical study. In: 4th conference on prediction, synergetic and more. Tomas Bata University in Zlin. 2001, p. 18-24, ISBN 80-7318-030-8.

[14] H. Hou, K.S. Andreas, F. Weller and A. Greiner, Carbon nanotubes and spheres produced by modified ferrocene pyrolysis, Chem Mater 14 (2002), pp. 3990-3994. 